\title{
Communication
}

\section{Insect Pests in Future Forests: More Severe Problems?}

\section{Christer Björkman *, Helena Bylund, Maartje J. Klapwijk, Ida Kollberg and Martin Schroeder}

Department of Ecology, Swedish University of Agricultural Sciences, P.O. Box 7044, SE-750 07 Uppsala, Sweden; E-Mails: helena.bylund@slu.se (H.B.); maartje.klapwijk@ slu.se (M.J.K.); ida.kollberg@slu.se (I.K.); martin.schroeder@slu.se (M.S.)

* Author to whom correspondence should be addressed; E-Mail: christer.bjorkman@ slu.se; Tel.: +46-18-671-532; Fax: +46-18-672-890.

Received: 11 February 2011 / Accepted: 24 March 2011 / Published: 4 April 2011

\begin{abstract}
A common concern is that damage by insects will increase in forests as a consequence of climate change. We are assessing the likelihood of this predicted outcome by examining how other factors (especially changes in forest management practices) may interact with effects of climate change. Here we describe the strategies for improving understanding of the causes of insect outbreaks and predicting the likelihood of insect-mediated damage increasing in the future. The adopted approaches are: $(i)$ analyses of historical data, (ii) comparison of life history traits of outbreak and non-outbreak species, (iii) experiments along climatic gradients to quantify the strength of trophic interactions, and (iv) modeling. We conclude that collaboration by researchers from many disciplines is required to evaluate available data regarding the complex interactions involved, to identify knowledge gaps, and facilitate attempts to progress beyond speculation to more robust predictions concerning future levels of insect damage to forests.
\end{abstract}

Keywords: forest insect pests; climate change; forest management; insect outbreak; time series; life history traits; population dynamics; trophic interactions; models

\section{Introduction}

It is commonly anticipated that forests will be more frequently and severely attacked by insect pests in the future [1-6], based on the presumption (often implicit) that population growth rates of insects will be enhanced by anticipated increases in temperature. However, although some severe outbreaks in 
recent years may have been coupled to climate change [5-8], alternative causes, such as changes in stand structure (especially large-scale increases in areas of even-aged forests reaching particularly vulnerable ages), and forest management, cannot be excluded [3,9]. In fact, despite the global warming that has occurred in recent decades there are still no clear general trends with respect to insect problems in forests [9]. This may be because the temperature changes have not been sufficiently large to cause clear trends, or they may have been too recent to have caused clear effects on insect populations to date. However, it is also possible that concerns that problems caused by insects will increase are exaggerated; perhaps we should not expect more frequent and severe insect attacks in the future. Furthermore, changes in both climatic variables and forest management practices will probably affect frequencies and levels of insect damage in future forests. Hence, by learning more about how these two sets of factors interact, we may identify ways to counteract adverse expected effects of climate change by selecting management methods that mitigate them.

In order to progress from speculative to more robust predictions concerning the frequency of insect damage in future forests we need to evaluate present knowledge thoroughly, and to collect and evaluate new data, using several approaches. In this paper we describe approaches being applied in a large-scale, multidisciplinary Swedish research program Future Forests (http://www.futureforests.se), which we believe to be the most profitable for addressing the following questions: $(i)$ Has insect damage either increased or decreased historically? (ii) Do outbreak species share common life history traits? (iii) What causes outbreaks? (iv) Is insect damage in forests likely to increase in the future? The second and third question have bearings on the fourth question since certain life history traits and processes involved in the regulation of populations are more likely to be affected by changes in climate (and management) than other traits and processes.

\section{Four Approaches}

In the Future Forests program we are using four approaches to address the four questions raised above: (i) analyses of historical data, (ii) species comparisons, (iii) empirical experiments, and (iv) modeling. To address the first question, regarding possible changes with time in the frequency and severity of previous insect attacks, we are using historical data of two kinds: a large European historical database (the oldest records dating from 1750), and time series data on insect damage and/or densities collected by similar methods and at the same sites over one or several decades. To address the second and third question, concerning causes of outbreaks, we are using species comparisons to identify possible inherent characteristics of outbreak species and experiments (partly based on analytical/conceptual models) to evaluate the role of extrinsic factors and the interactions between influential factors. To address the last question, concerning the likelihood that outbreaks will be more common and severe in the future we will use population models parameterized using results from the studies mentioned above and predicted future climate scenarios.

\subsection{Historical Data to Predict the Future}

In the context of observed and predicted climate change, analyses of long-term datasets have proven to be valuable for identifying relationships between weather patterns and fluctuations in insect populations. However, long-term datasets have to be analyzed and interpreted cautiously, since the 
quality of both time series data of population densities and correlated data has to be considered. Correlations between population fluctuations and weather patterns do not necessarily mean there is a causal relationship between them if the mechanisms responsible for the variation in population dynamics are not known. Further, when interpreting trends and changes in population dynamics over time, we need to consider both abiotic and biotic factors, since (for instance) changes in forest management practices and forest composition may affect them. Two types of long-term data series on forest insects are used in these analyses: records of outbreaks covering large temporal and spatial scales, and data acquired from monitoring population densities in local stands. Long-term datasets have become important tools for correlating observed population fluctuations to observed weather patterns. This approach has been used with varying degrees of success for various species [10-17], revealing patterns and correlations related to the weather. Using long-term datasets changes in outbreak behavior of several species have been detected. For instance, larch bud moth populations exhibited synchronized, Alpine-wide nine-year cyclic fluctuations until the 1980s, after which the synchronization of the fluctuations ceased and outbreaks were more localized [18]. In addition, the outbreak ranges of forest defoliating geometrid moths have extended to more continental locations, i.e., outbreaks have occurred in areas where the species were previously only present at endemic levels [19]. Increases in winter survival rates (and hence higher population growth rates) due to increases in winter temperatures, are suggested explanations for the outbreak range expansion of these geometrid moth species [11,19]. This indicates that changes in the climate can affect the risk for outbreaks of forest defoliating insects when outbreak and distribution ranges are changing.

An additional challenge posed by time-series data is that both population and outbreak dynamics clearly have not only a temporal component, but also a spatial component. Spatial synchrony has been observed for many outbreaking forest insect species [20,21]. Insects dispersing between localities during outbreaks may contribute to some of the synchrony, but environmental stochasticity may be more significant $[22,23]$. From this perspective, the weather may influence not only the start of an outbreak, but also its synchrony, and thus the scale of damage, emphasizing the importance of acquiring and rigorously examining datasets describing changes in populations of species of interest over long temporal and spatial scales.

Of course, abiotic factors do not solely affect forest defoliating insect species, they also affect the trees and other ecosystem components in forests. Notably, it has been thoroughly established that disturbances, such as storm fellings, strongly affect the probability of bark beetle outbreaks. Forest management and policies are further important aspects to consider since the probability of devastating outbreaks may also be dependent on forest composition, tree health, forest age, and other factors. Thus, in addition to correlating weather patterns to population dynamics, effects of forest management practices also need to be considered.

Most long-term series of recorded outbreaks, and to some extent long-term series of population density estimates, are records of forest defoliators. Therefore, the main data sets included in our study will largely be time-series of recorded damage, supplemented by light-trap catches, although they mainly measure activity of defoliators. Several chewing and boring insects, mainly in Hungary and in Sweden, will be considered. A first step in the analyses is to relate long-term trends in variables such as the outbreak frequency or area defoliated per year to trends in weather patterns. 
The results of the analyses will be integrated with other information in other parts of the project and will hopefully lead to a better understanding of the effects of weather and help us to evaluate and forecast the probabilities of insect outbreaks in future forests. In conclusion, ecological knowledge of mechanisms affecting the population dynamics of insect pests is essential for understanding their outbreak dynamics and predicting future outbreak risks in a changing climate [24]. However, for interpreting results and forecasting outbreaks, information on major forest management practices and forest composition is equally important.

\subsection{Species Comparisons}

Can life history traits of insects inform us about their outbreak propensity? Researchers focusing on this question have attempted to identify traits within different groups of forest insects that distinguish species with outbreak dynamics from non-outbreak species. It is likely that certain life history traits are more sensitive to changes in climate and management and such knowledge would therefore be valuable when trying to make more accurate predictions about the future. Only a few forest insects are notorious for the damage they cause to forests. The fluctuations in their populations have been proposed to be driven by host plant factors [25], natural enemies [26], weather conditions [27], or possibly factors intrinsic to the insect species, such as their life history traits [28] and ecology [29,30]. However, the true causes of the fluctuations may lie in interactions between these factors. The life history trait approach has received relatively little attention, but if outbreak species can be shown to have common traits, it might be more straightforward to determine whether their putative higher population variability is linked to certain interactions acting through host plant, natural enemy or climatic effects.

Forest Macrolepidoptera species, that are either spring or gregarious summer feeders, have broader diets, greater fecundity, and are more likely to exhibit outbreak dynamics than non-outbreak Lepidoptera [29]. In a similar study on Diprionid (sawflies, Figure 1) life history traits. Larsson et al. [30] concluded that gregariousness is the most important trait determining outbreak propensity within this group, and that Diprionid resin-acid defense (regurgitation of resin) capacity, is positively related to group size (more is better). Their main conclusion is that gregarious species have a defense capability strong enough to frequently survive in high numbers on low resin-acid needles. In addition, the fecundity of these groups' suffering is less adversely affected by high resin-acid concentrations [31].

A book chapter by Koricheva et al. [32], includes a third group containing several well-known outbreak species, the bark beetles. In the analysis, data were collected on life history traits of three subfamilies of bark beetles: the Hylesininae, Ipinea, and Scolytinae. Similar, fairly low proportions of monophagous (feeding on only one plant genus) and polyphagous (feeding on more than one plant genus) bark beetles are outbreak species, i.e., at least one outbreak of the species has been reported. Overall, bark beetle species seem to occur more frequently on coniferous trees than deciduous trees, and there are also proportionally more outbreak species than non-outbreak species on coniferous trees. The average body size of outbreak species also tends to be larger than that of non-outbreak species, while the sub-families seem to have the same average size. 
Figure 1. Gregariousness or group-living is typical for outbreak species among needle-eating lepidopterans and sawflies, here represented by the European pine sawfly, Neodiprion sertifer.

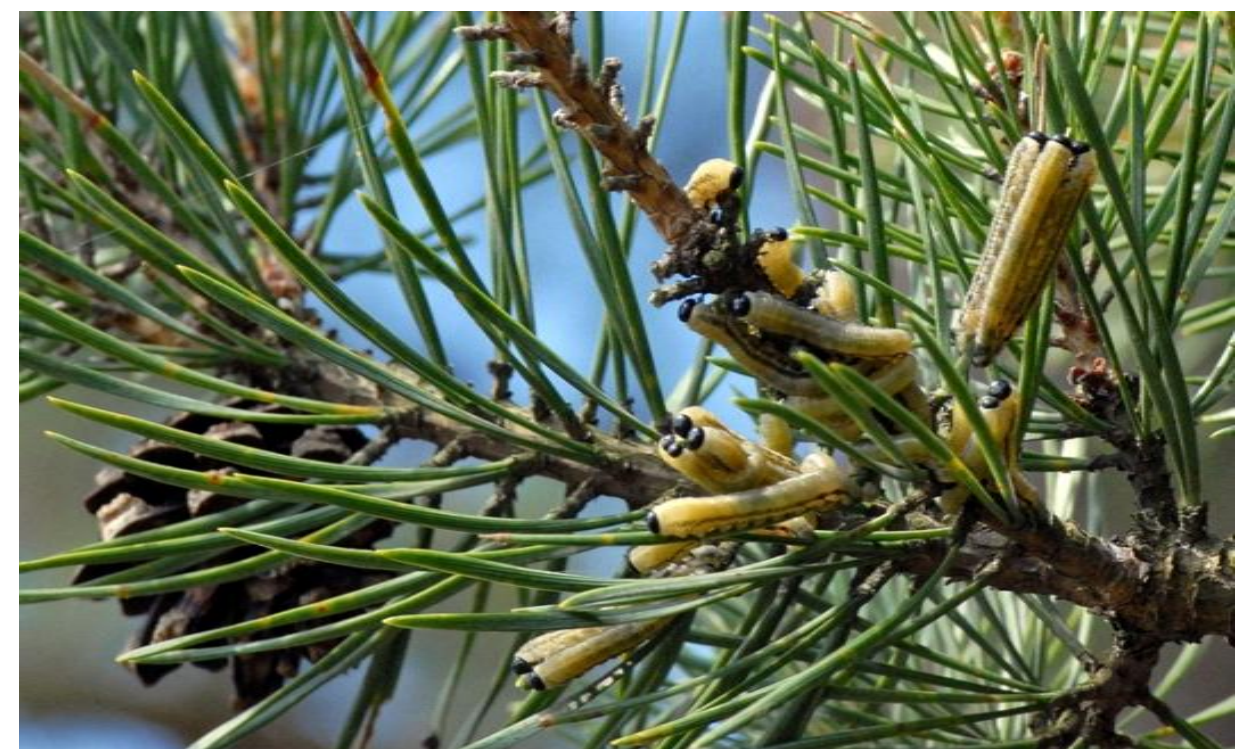

The body size and gallery length might be indicators of reproductive output, since larger individuals of a given species are thought to have a larger egg load [33] and gallery length might be an indicator of the number of larvae in a gallery. If so, the longer galleries and the difference in size between outbreak and non-outbreak species may indicate that that the former generally have higher reproduction potential than the latter.

Analyses of both Macrolepidoptera and the sawflies indicate that gregariousness is a key factor for outbreaks in defoliating insects. Gregariousness is not a trait that can be easily defined for bark beetles, since their galleries generally host multiple larvae. One of the obvious benefits of gregariousness is that both risks of predation and defense efforts are spread among many individuals. However, spring feeding is proposed to lead to outbreaks when egg hatching and leaf flush are synchronized [34-37], regardless of whether or not the species is gregarious, whereas phenology does not play an important role in Diprionid sawfly ecology. The reproductive success of bark beetles is more closely related to tree vigor than to tree phenology, and is thus less predictable, and dependent on drought spells or storm felling. Both Hunter [29] and Larsson et al. [30] have proposed gregariousness to be most important in interactions with natural enemies. Diet breadth was not important for separating outbreak species from the non-outbreak species of either Diprionid sawflies or bark beetles. The analyses of the bark beetle data indicate that most of the differences within this group can be attributed to differences (other than body size) between the subfamilies, but not necessarily within the subfamilies between outbreak and non-outbreak species [32]. Identified life history traits that differ between outbreak and non-outbreak species seem to indicate that they are not particularly sensitive to external factors and that the initiation of an outbreak probably depends on a combination of factors that need to be considered together to predict outbreak risks.

In the context of climate change, level of gregariousness is a plastic trait and is likely to be influenced by changes in the external environment. However, differences between solitary and 
gregarious species will most certainly remain. Spring-feeding phenology could be affected by the increasing spring temperatures; bottom-up selection pressure will force selection towards shifting hatching dates [38]. Fecundity might also increase with increasing temperatures [39], with possible effects on population growth rates and outbreak potential.

To be able to make predictions about species responses to predicted changes in climate, it is important to look beyond direct responses to weather conditions or parameters like temperature. As long as the cause of extreme population fluctuations, cyclic or not, is not fully understood or contributed to external factors, like weather conditions, life history traits or species ecology should not be neglected in attempts to predict future outbreak potential. Some species are more sensitive to extreme fluctuations than others, if we can identify the source of this sensitivity, this will take us a step closer to predicting and possibly preventing more damage in the forests of the future.

\subsection{Experiments}

In order to make accurate predictions about population dynamics under future climate scenarios we need to identify processes and interactions that drive population fluctuations. Species do not exist in isolation, but are embedded in a web of trophic interactions. Therefore, population fluctuations are affected by host plant factors, i.e., bottom-up effects, and by natural enemies, i.e., top-down effects. In both terrestrial and marine systems, sensitivity to temperature increases with increasing trophic level, indicating that top-down effects become increasingly strong relative to bottom-up effects as temperatures rise [40-42]. We are using a system involving the European pine sawfly Neodiprion sertifer (Hymenoptera; Diprionidae) - an intensively studied species that has been previously used for studies on trophic interactions [31,43-48] — to study climatic effects on interactions between trophic levels. The empirical component of our work focuses on known drivers/interactions along a latitudinal gradient in Sweden: Asa $\left(56^{\circ} \mathrm{N}\right)$, Uppsala $\left(59^{\circ} \mathrm{N}\right)$, and Vindeln $\left(64^{\circ} \mathrm{N}\right)$. Latitudinal gradients provide natural variation in climatic conditions, especially temperature. However, the results need to be carefully interpreted since many other factors vary as well. By using this well-studied system we can measure covariables known to influence the performance of $N$. sertifer and include them in estimations of the effects of factors of interest. In addition, we will use translocation experiments to investigate the role of local adaptation. To evaluate the results of field studies we can use controlled laboratory experiments. The purpose of the studies is to estimate $N$. sertifer performance in terms of survival and development in different developmental stages, evaluating (inter alia) the role of food quality and natural enemies, i.e., predators and parasitoids (Figure 2). As natural enemies might be more active under increased temperatures we expect mortality due to natural enemies to increase with temperature. In addition, high temperatures reduce developmental times, thereby reducing the "window" for predation/parasitism, possibly resulting in the opposite pattern or no significant differences at all. Further, if the pressure from natural enemies increases, other factors such as group size could become more important since a large group size is often advantageous for group-feeding insects. For $N$. sertifer, food quality might become more important as temperature increases, since the larvae use pine resins in their anti-predator defense. 
Figure 2. Not only is the forest insect pest affected by changes in the environment, e.g., the climate, but also their host plants and natural enemies. In order to predict the risk for more insect damage in the future we need to understand how bottom-up (through the host tree) and top-down (through the natural enemies) interactions are affected.

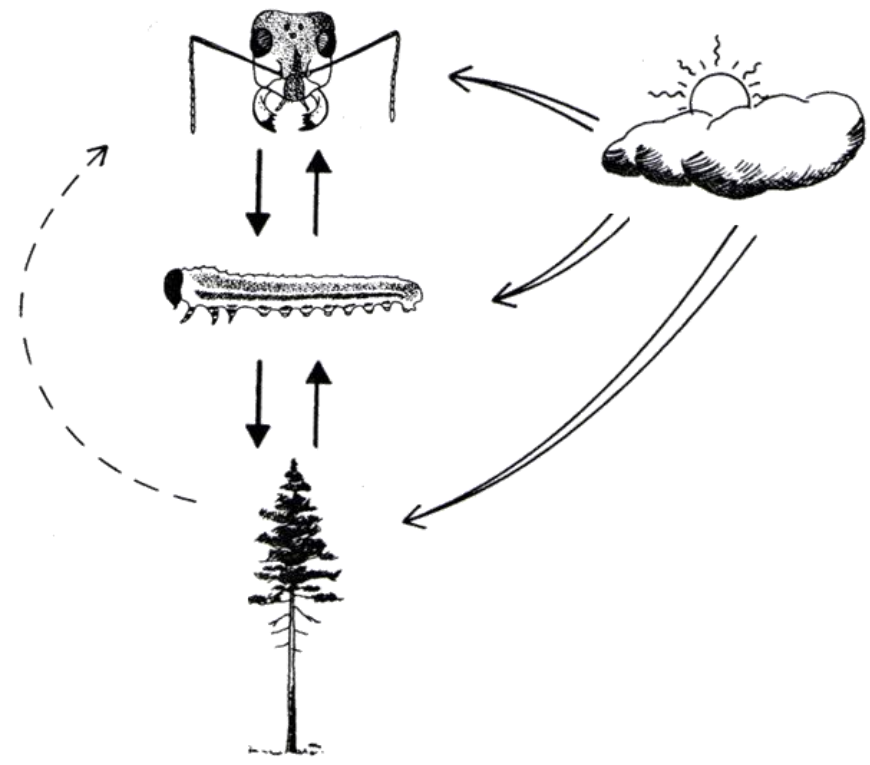

Host resistance and natural enemies are important determinants of larval mortality of $N$. sertifer, but they are not considered to be sufficiently strong to drive the population dynamics of the species. Instead, small mammals are suggested to regulate populations of $N$. sertifer at endemic levels [47]. Release from small mammal predation pressure could lead to increases in population densities [49]. Decreasing numbers of small mammals in Sweden seem to be linked to increased temperatures and reductions in snow cover during winter [50]. However, small mammals alone cannot be responsible for population regulation, or the lack thereof, since no strong relationship between mammal density and outbreak propensity has been observed in the past. It is more likely that reductions in small mammal densities coincide with changes in other regulating factors acting in the same direction on sawfly population growth rates. Our research aims to identify and quantify the interactions between different trophic levels, enabling the formulation of a conceptual and (possibly) an analytical model to improve predictions of the performance of forest insects and the likelihood of outbreaks under future climate scenarios.

\subsection{Models}

Modeling is a useful and often powerful approach for gaining insights into complex interactions, e.g., potential effects of changes in climate and forest management on the likelihood of outbreaks of forest insects. Here we describe one such attempt concerning bark beetles.

Bark beetles may cause major ecosystem disturbances by killing large volumes of conifer trees during outbreaks. Such outbreaks may be triggered and driven by weather and forest management practices [7]. Using an ecosystem modeling approach we can evaluate how different climate change and forest management scenarios may affect risks of future outbreaks of the spruce bark beetle, as follows: ( $i$ ) A bark beetle population model predicting between-generation dynamics is developed, 
(ii) the bark beetle model is implemented into an existing vegetation model, LPJ-GUESS, to assess interactions between the spruce bark beetle and its host tree, Norway spruce, and (iii) different scenarios regarding climate change and forest management are simulated and consequences for timber production and tree mortality caused by the spruce bark beetle are analyzed.

Outbreaks by the spruce bark beetle may be triggered by storm disturbances, which provide the beetles with a surplus of breeding material with weak (or no) defense. The densities of bark beetle egg galleries in the colonized wind-felled trees will be low, releasing them from the strong intraspecific competition they usually experience [51], hence the number of progeny per female will increase. Thus, in the summers following a storm-felling the beetle populations may increase to sufficiently high densities for the beetles to overcome the defenses of living trees [52]. In addition, warm, dry summers may increase the risk of outbreaks by reducing tree vigor and promoting bivoltinism (i.e., two generations in the same summer).

The bark beetle population model is structured within generations based on the following life stages: beetles surviving hibernation (and hence densities during the flight period), colonization of wind-felled trees and living trees (successful colonization of living trees requires a beetle density above a threshold value) and reproductive success (based on intraspecific competition). The model is grid-based (i.e., operates in specified areas), but not spatially explicit within grid areas.

LPJ-GUESS is a process-based framework for modeling vegetation dynamics and biogeochemistry designed for regional to global applications $[53,54]$. In LPJ-GUESS, the process-based biogeochemistry of the widely used Lund-Potsdam-Jena Dynamic Global Vegetation Model (LPJ-DGVM) is combined with a detailed representation of forest stand structure and dynamics $[55,56]$. The model is driven by weather variables, e.g., temperature, precipitation and solar radiation.

Forest management scenarios that will be analyzed include scenarios with different rotation periods, different tree species mixtures, continuous forestry (i.e., no clear-cuts) and present practices (with clear-cuts). Selected time-periods for the climate change modeling are: 1961-1990 (reference period), 2011-2040 and 2071-2100. The model is developed in collaboration between Future Forests and the SWECIA project (http://www.mistra-swecia.se).

\section{Conclusions and Future Directions}

We conclude that there seems to be increasing awareness among the forest insect pest research community of the need to study possible effects of climate change and changes in management practices in concert. Further compilation and re-analysis of available data concerning aspects such as insect performance and population dynamics in different environments should provide additional understanding of likely effects of changes in the climate and forest management practices on insect-mediated damage. Meta-analyses of studies of insect performance and population growth or dynamics along various kinds of climatic gradients, e.g., latitudinal and altitudinal, may be particularly fruitful.

New experiments that simultaneously study the responses of several players (insects, trees, microorganisms, and natural enemies) in trophic webs are needed. Most previous experiments have only studied responses of the target insect or interactions between two trophic levels (insect-tree or insect-natural enemies), although we know that in nature interactions generally occur between more 
than two trophic levels. Further, since the outcome of complex interactions is difficult to predict, and assessing them requires major efforts, identification and concentration on species that can serve as model organisms, representing a group of insects, would be highly desirable (cf. Experiments Section above).

Another aspect that is linked to trophic interactions is that few pests act in isolation-it is well known that attacks by one pest or pathogen may increase the likelihood of attacks by other pests or pathogens. Such 'damage chains' may involve two or several species. For example, defoliation by the sawfly $N$. sertifer makes pine trees more vulnerable to attack by pine shoot beetles (Tomicus spp.). At present we can only speculate about how changes in management methods and climate change may affect damage chains. However, it seems likely that a warmer climate may favor several species in some damage chains and, hence, substantially increase the probability of severe damage.

In conclusion, there is an urgent need to start evaluating existing data and designing new experiments. Due to the complexity of the interactions involved, close collaboration is required between researchers focusing on different agents of forest damage (e.g., insects and pathogens), and other relevant aspects, e.g., plant physiology, forest management, historical and social dimensions. The Future Forests program is intended to encourage and facilitate such collaborations in order to formulate and apply an integrated approach for future analyses.

\section{Acknowledgements}

Financial support was provided by the project Future Forests program and the Swedish Research Council for Environment, Agricultural Sciences, and Spatial Planning (FORMAS).

\section{References}

1. Bale, J.S.; Hayward, S.A.L. Insect overwintering in a changing climate. J. Exp. Biol. 2010, 213, 980-994.

2. Fleming, R.A.; Candau, J.N. Influences of climatic change on some ecological processes of an insect outbreak system in Canada's boreal forests and the implications for biodiversity. Environ. Monit. Assess. 1998, 49, 235-249.

3. Logan, J.A.; Régnière, J.; Powell, J.A. Assessing the impacts of global warming on forest pest dynamics. Front. Ecol. Environ. 2003, 1, 130-137.

4. Shaver, G.R.; Canadell, J.; Chapin, F.S.; Gurevitch, J.; Harte, J.; Henry, G.; Ineson, P.; Jonasson, S.; Melillo, J.; Pitelka, L.; Rustad, L. Global warming and terrestrial ecosystems: A conceptual framework for analysis. BioScience 2000, 50, 871-882.

5. Tenow, O.; Nilssen, A.C.; Holmgren, B.; Elverum, F.; An insect (Argyresthia retinella, Lep., Yponomeutidae) outbreak in northern birch forests, released by climatic changes? J. Appl. Ecol. 1999, 36, 111-122.

6. Williams, D.W.; Liebhold, A.M. Forest defoliators and climatic change-potential changes in spatial distribution of outbreak of western spruce budworm (Lepidoptera, Tortricidae) and gypsy moth (Lepidoptera, Lymantriidae). Environ. Entomol. 1995, 24, 1-9. 
7. Raffa, K.F.; Aukema, B.H.; Bentz, B.J.; Carroll, A.L.; Hicke, J.A.; Turner, M.G.; Romme, W.H. Cross-scale drivers of natural disturbances prone to anthropogenic amplification: The dynamics of bark beetle eruptions. BioScience 2008, 58, 501-517.

8. van Bael, S.A.; Aiello, A.; Valderrama, A.; Medianero, E.; Samaniego, M.; Wright, S.J. General herbivore outbreak following an El Nino-related drought in a lowland Panamanian forest. J. Trop. Ecol. 2004, 20, 625-633.

9. Büntgen, U.; Frank, D.; Liebhold, A.; Johnson, D.; Carrer, M.; Urbinati, C.; Grabner, M.; Nicolussi, K.; Levanic, T.; Esper, J. Three centuries of insect outbreaks across the European Alps. New Phytol. 2009, 182, 929-941.

10. Ozaki, K.; Fukuyama, K.; Isono, M.; Takao, G. Simultaneous outbreaks of three species of larch web-spinning sawflies: Influences of weather and stand structure. For. Ecol. Manage. 2004, 187, 75-84.

11. Bylund, H.; Hofgaard, A.; Ball, J.P.; Danell, K.; Callaghan, T.V. Climate and the population dynamics of two insect outbreak species in the north. Ecol. Bull. 1999, 47, 54-62.

12. Kress, A.; Saurer, M.; Büntgen, U.; Treydte, K.S.; Bugmann, H.; Siegwolf R.T.W. Summer temperature dependency of larch budmoth outbreaks revealed by Alpine tree-ring isotope chronologies. Oecologia 2009, 160, 353-365.

13. Gray, D. The relationship between climate and outbreak characteristics of the spruce budworm in eastern Canada. Climatic Change 2008, 87, 361-383.

14. Cooke, B.J.; Roland, J. The effect of winter temperature on forest tent caterpillar (Lepidoptera; Lasiocampidae) egg survival and population dynamics in northern climates. Environ. Entomol. 2003, 32, 299-311.

15. Grimalskii, V.I. Influence of doughts on massive reproduction of needle-eating pests of pine. Soviet J. Ecol. 1977, 8, 94-96.

16. Baltensweiler, W.; Weber, U.M.; Cherubini, P. Tracing the influence of larch-bud-moth insect outbreaks and weather conditions on larch tree-ring growth in Engadine (Switzerland). Oikos 2008, 117, 161-172.

17. Tran, J.K.; Ylioja, T.; Billings, R.F.; Régnière, J.; Ayres, M.P. Impact of minimum winter temperatures on the population dynamics of Dendroctonus frontalis. Ecol. Appl. 2007, 17, 882-899.

18. Esper, J.; Büntgen, U.; Frank, D.C.; Nievergelt, D.; Liebhold, A. 1200 years of regular outbreaks in alpine insects. P. Roy. Soc. B.-Biol. Sci. 2007, 274, 671-679.

19. Jepsen, J.U.; Hagen, S.B.; Ims, R.A.; Yoccoz, N.G. Climate change and outbreaks of the geometrids Operophtera brumata and Epirrita autumnata in subarctic birch forest: Evidence of a recent outbreak range expansion. J. Anim. Ecol. 2008, 77, 257-264.

20. Liebhold, A.; Kamata, N. Introduction-Are population cycles and spatial synchrony a universal characteristic of forest insect populations? Popul. Ecol. 2000, 42, 205-209.

21. Klemola, T.; Huitu, O.; Ruohomäki, K. Geographically partitioned spatial synchrony among cyclic moth populations. Oikos 2006, 114, 349-359.

22. Peltonen, M.; Liebhold, A.M.; Bjørnstad, O.N.; Williams, D.W. Spatial synchrony in forest insect outbreaks: Roles of regional stochasticity and dispersal. Ecology 2002, 83, 3120-3129. 
23. Williams, D.W.; Liebhold, A.M. Spatial synchrony of spruce budworm outbreaks in eastern North America. Ecology 2000, 81, 2753-2766.

24. Klapwijk, M.J.; Battisti, A.; Ayres, M.P.; Larsson, S. Assessing the impact of climate change on outbreak potential. In Insect Outbreaks Revisited; Barbosa, P., Schultz, J.C., Letourneau, D., Eds.; Blackwell Publishing Ltd: Oxford, UK, 2011, accepted.

25. White, T.C.R. Plant vigour versus plant stress: A false dichotomy. Oikos 2009, 118, 807-808.

26. Population Cycles: The Case for Trophic Interactions; Berryman, A.A., Ed.; Oxford University Press: New York, NY, USA, 2002.

27. Martinat, P.J. The role of climatic variation and weather on forest insect outbreaks. In Insect Outbreaks; Barbosa, P., Schultz, J.C., Eds.; Academic Press, Inc.: San Diego, CA, USA. 1987; pp. 241-268.

28. Benton, T.G.; St Clair, J.J.H.; Plaistow, S.J. Maternal effects mediated by maternal age: From life histories to population dynamics. J. Anim. Ecol. 2008, 77, 1038-1046.

29. Hunter, A.F. Traits that distinguish outbreaking and nonoutbreaking macrolepidoptera feeding on northern hardwood trees. Oikos 1991, 60, 275-282.

30. Larsson, S.; Björkman, C; Kidd, N.A.C. Outbreaks in diprionid sawflies: Why some species and not others? In Sawfly Life History Adaptations to Woody Plants; Wagner; M.R., Raffa, K.F., Eds.; Academic Press: San Diego, CA, USA, 1993; pp. 453-483.

31. Björkman, C.; Larsson, S.; Bommarco, R. Oviposition preferences in pine sawflies: A trade-off between larval growth and defence against natural enemies. Oikos 1997, 79, 45-52.

32. Koricheva, J.; Klapwijk, M.J.; Björkman, C. Implications of life history traits and host plant characteristics for insect herbivore population dynamics. In Insect Outbreaks Revisited; Barbosa, P., Schultz, J.C., Letourneau, D., Eds.; Blackwell Publishing Ltd: Oxford, UK, 2011, accepted.

33. Honek, A. Intraspecific variation in body size and fecundity in insects-A general relationship. Oikos 1993, 66, 483-492.

34. van Asch, M.; Visser, M.E. Phenology of forest caterpillars and their host trees: The importance of synchrony. Annu. Rev. Entomol. 2007, 52, 37-55.

35. Dixon, A.F.G. Climate change and phenological asynchrony. Ecol. Entomol. 2003, 28, 380-381.

36. van Dongen, S.; Backeljau, T.; Matthysen, E.; Dhondt, A.A. Synchronization of hatching date with budburst of individual host trees (Quercus robur) in the winter moth (Operophtera brumata) and its fitness consequences. J. Anim. Ecol. 1997, 66, 113-121.

37. Hunter, A.F.; Elkinton, J.S. Effects of synchrony with host plant on populations of a spring-feeding Lepidopteran. Ecology 2000, 81, 1248-1261.

38. Visser, M.E.; Both, C. Shifts in phenology due to global climate change: The need for a yardstick. P. Roy. Soc. B.-Biol. Sci. 2006, 272, 2561-2569.

39. Uvarov, B.P. Insects and climate. Trans. Ent. Soc. Lond. 1931, 79, 1-232.

40. O'Connor, M.I. Warming strengthens an herbivore-plant interaction. Ecology 2009, 90, 388-398.

41. Berggren, Å.; Björkman, C.; Bylund, H.; Ayres, M.P. The distribution and abundance of animal populations in a climate of uncertainty. Oikos 2009, 118, 1121-1126.

42. Björkman, C.; Berggren, Å; Bylund, H. Causes behind insect folivory patterns in latitudinal gradients. J. Ecol. 2011, 99, 367-369. 
43. Hanski, I. Small mammal predation and the population dynamics of Neodiprion sertifer. In Population Dynamics of Forest Insects; Watt, A.D., Leather, S.R., Hunter, M.D., Kidd, N.A.C., Eds.; Intercept: Andover, MA, USA and Hampshire, UK, 1990; pp. 253-262.

44. Holling, C.S. Some characteristics of simple types of predation and parasitism. Can. Entomol. 1959, 91, 385-398.

45. Kouki, J.; Lyytikäinen-Saarenmaa, P.; Henttonen, H.; Niemelä, P. Cocoon predation an diprionid sawflies: The effect of forest fertility. Oecologia 1998, 116, 482-488.

46. Larsson, S.; Ekbom, B.; Björkman, C. Influence of plant quality on pine sawfly population dynamics. Oikos 2000, 89, 440-450.

47. Olofsson, E. Mortality factors in a population of Neodiprion sertifer (Hymenoptera, Diprionidae). Oikos 1987, 48, 297-303.

48. Pschorn-Walcher, H. The ecology of Neodiprion sertifer (Geoffr. ) (Hymenoptera: Diprionidae) and a review of its parasite complex in Europe. Commonw. Inst. Biol. Contr. Tech. Bull. 1965, 5, 33-97.

49. Hanski, I.; Parviainen, P. Cocoon predation by small mammals, and pine sawfly population dynamics. Oikos 1985, 45, 125-136.

50. Hörnfeldt, B. Long-term decline in numbers of cyclic voles in boreal Sweden: Analysis and presentation of hypotheses. Oikos 2004, 107, 376-392.

51. Anderbrant, O. Gallery construction and oviposition of the bark beetle, Ips typographus (Coleoptera, Scolytidea) at different breeding densities. Ecol. Entomol. 1990, 15, 1-8.

52. Christiansen, E. Ips Ceratocystis - Infection of the Norway spruce-What is the deadly dosage. J. Appl. Entomol. 1985, 99, 6-11.

53. Sykes, M.T.; Prentice, I.C.; Smith, B.; Cramer, W.; Venevsky, S. An introduction to the European terrestrial ecosystem modelling activity. Global Ecol. Biogeogr. 2001, 10, 581-593.

54. Smith, B.; Prentice, I.C.; Sykes, M.T. Representation of vegetation dynamics in the modelling of terrestrial ecosystems: Comparing two contrasting approaches within European climate space. Global Ecol. Biogeogr. 2001, 10, 621-637.

55. Miller, P.A.; Giesecke, T.; Hickler, T.; Bradshaw, R.H.W.; Smith, B.; Seppa, H.; Valdes, P.J.; Sykes, M.T. Exploring climatic and biotic controls on Holocene vegetation change in Fennoscandia. J. Ecol. 2008, 96, 247-259.

56. Sitch, S.; Smith, B.; Prentice, I.C.; Arneth, A.; Bondeau, A.; Cramer, W.; Kaplan, J.O.; Levis, S.; Lucht, W.; Sykes, M.T.; Thonicke, K.; Venevsky, S. Evaluation of ecosystem dynamics, plant geography and terrestrial carbon cycling in the LPJ dynamic global vegetation model. Global Change Biol. 2003, 9, 161-185.

(C) 2011 by the authors; licensee MDPI, Basel, Switzerland. This article is an open access article distributed under the terms and conditions of the Creative Commons Attribution license (http://creativecommons.org/licenses/by/3.0/). 